\title{
Back analysis of tensile test drilled shafts and barrettes
}

San-Shyan Lin

Professor, Dept. of Harbor and River Eng., National Taiwan Ocean University, Keelung, Taiwan, 20224.

Adjunct Professor, Swinburne University of Technology, Sarawak Campus, Malaysia.

E-mail: sslin46@gmail.com

Chia-Hung Lai

Graduate Student, Dept. of Harbor and River Eng., National Taiwan Ocean University, Keelung, Taiwan, 20224.E-mail: seadolphin1018@yahoo.com

Jen-Cheng Liao

Research Fellow, Taiwan Construction Research Institute, New Taipei City, Taiwan. E-mail: jcliao@tcri.org.tw

Dominic E.L. Ong, School of Engineering and Built Environment, Griffith University, Nathan Campus, Australia. E-mail:d.ong@griffith.edu.au

ABSTRACT. This paper presents a method to interpret the tensile test results for a concrete pile when the concrete is stressed beyond its tensile limit, which results in anomalies in the strain gage data that is collected during active load testing. Two drilled shafts and two barrettes are studied using the proposed method. Any pile loads that are computed using strain data and which are greater than the specific applied load are discarded because these results are physically impossible. A Spline function is then used to fit the remaining valid data for pile load along the depth. Using the fitted Spline function and assuming that the behavior at the pile/soil interface can be modeled as a hyperbolic model, a back-analysis method is used to determine the parameters for the model. The software, SHAFT is used to compare the results for the back analysis and the measured gage data. It is found that the back-analysis method that is used in this study gives a reasonable interpretation of the pile loading test results, such as the t-z curves, using the pile force and a depth fitting function.

KEYWORDS: Back analysis; drilled shaft; barrette; tensile test. 


\section{Introduction}

A tensile loading test for a pile is used either to verify the carrying capacity of the preliminary design or to determine the ultimate capacity of a pile foundation. Strain gages are often installed at specific depths along the pile to measure strain distribution, which allows a better interpretation of the test results. The measured strain data is converted to a distribution of the shaft resistance. The conversion procedure requires the property of the axial stiffness of the tested pile. The pile is composed of concrete and steel for a drilled shaft or a barrette. Concrete is a highly variable material, and the properties of concrete that is supplied by different suppliers or of different batches can differ. Differences in the quality of construction can also affect the properties of the concrete, especially for a drilled shaft or a barrette which are often formed using tremie pipe. It is difficult to ensure homogeneity of concrete properties along the shaft, so the elastic modulus of the concrete is not a constant, but is a function of the strain, $\varepsilon$, or the strain rate.

Tensile tests in Taiwan involve holding the rebar cage on the test pile head to pull it out. The test results are affected by the strength of the bond between the concrete and the steel interface. For an applied load of greater than a specific magnitude, the rebar and concrete can separate and/or the concrete can crack, so the measured strain can be unreliable, which produces problems for data conversion. It is known that the computed loads at any point in a pile cannot be greater than the load that is applied at the head, but for local pile load test reports, at some points the calculated pile load is ignored because there is anomalously high measured strain data. This is usually assumed to occur because of a malfunction of the gage and the data is ignored.

Current methods that are used to convert strain data into pile loads were assessed in detail by Lam and Jefferis (2011). The most common method uses the measured data from the uppermost gage near the pile head (Brown, Hyde, and Anderson 2006; Deschamps and Richards 2005; Siegel 2010). This method determines the relationship between the strain and the pile modulus and assumes that the relationship between elastic modulus and strain that is 
developed at the gage level near the pile head can also be applied to the remainder of the pile. This method is known as the secant modulus method. Other methods include the tangent modulus method, the implicit method and the linear elastic method (Fellenius 1989 and 2001; Sellers 2003; and Omer, Delpak, and Robinson 2002). The tangent modulus method considers the modulus of the pile materials at all levels at which a gage is installed. The study by Lam and Jefferis (2011) concluded that the secant modulus method is the most accurate for a compressive test pile. However, none of these methods consider the effect of concrete fracture or cracking on pile stiffness. A linear decreasing axial stiffness method was used by Sinnerich (2012) to determine the concrete fracture that results from an applied tensile load. The pile stiffness decreases because the concrete cross-sectional area changes from an initial full crosssectional area down to zero. The study did not determine the effect of concrete modulus. The assumption that - "the relationship between the elastic modulus and the strain that is developed at the gage level near the pile head can also be applied to the remainder of the pile"- is not valid if the uppermost gage level is affected by the concrete fracture. In this case, the tangent modulus is used.

This paper presents a novel method to interpret the tensile test results for a concrete pile when the concrete is stressed beyond its tensile limit, which leads to anomalies in the strain gage data that is collected during active load testing. Two drilled shafts and two barrettes are studied using the proposed method. The collected strain gage data is converted to pile load along the depth. Any pile loads that are computed using the strain data and which are greater than the specific applied load are deemed to be physically impossible and are ignored. A Spline function is then used to fit the remaining valid data for a pile load along the depth. Using the Spline function and assuming that the behavior between pile and soil interface can be modeled as a hyperbolic model, a back-analysis method is then used to determine the parameters for the model. The t-z curves for each soil layer and the bedrock after back analysis are compared to those for the conventional method using the software, SHAFT (Reese et al. 2018). 


\section{Derivation of the secant and tangent modulus of concrete}

The secant modulus of concrete for a tested pile is often interpreted using the strain data that is collected at the uppermost rebar gages near the pile head. In order to calculate the stress level in a drilled shaft, it is assumed that the strain measure is representative of the entire cross section (Lam and Jefferis 2011). It is also assumed that the relationship between the modulus and the strain relationship at the uppermost gage level can be applied to the remainder of the pile. One more assumption that the method requires is that the frictional resistance between the soil and the pile from the ground surface to the uppermost gage is neglected for a specific applied load at the head. In this regard, the uppermost set of rebar gages must be placed near the pile head to minimize the loss of the pile load due to shaft resistance. The end effect or the Saint Venant Principle is also important (Lam and Jefferis 2011). In general, the rebar gage is installed at a depth that is approximately equal to the width of the shaft. In Taiwan, most pile load tests install the uppermost rebar gage $1 \mathrm{~m}$ to $3 \mathrm{~m}$ below the pile head. The second gage is installed at the cut-off level. The procedures for computing the secant modulus of concrete $E_{c}$ are as follows:

The steel stress $\sigma_{s}$ is written as

$\sigma_{S}=E_{S} \times \varepsilon_{S}$

where $E_{S}$ is the elastic modulus of the steel and $\varepsilon_{S}$ is the strain that is measured by rebar strain gage. The steel force $f_{s}$ is the product of the steel stress and the cross-sectional area of the steel $A_{s}$. Similarly, the concrete force $f_{c}$ is the difference between the steel force $f_{s}$ and the force that is applied at the pile head.

If the strain is compatible:

$\varepsilon_{c}=\varepsilon_{S}$

Subsequently, the concrete modulus is calculated as:

$E_{c}=\frac{f_{c}}{A_{c} \times \varepsilon_{c}}=\frac{\sigma_{c}}{\varepsilon_{c}}$,

where $\sigma_{c}$ is the concrete stress. The pile load is the sum of the product of the concrete stress and the concrete area and the steel stress and the steel area: 
$P=\sigma_{c} \times A_{c}+\sigma_{s} \times A_{s}$

The modulus values that are calculated using Equation (3) are often plotted against strain. This relationship is then modeled using a best fit curve, such as an exponential or a polynomial equation. For an exponential equation, the relationship between $E_{c}$ and strain is expressed as: $E_{c}=k_{1} \times \exp \left(k_{2} \varepsilon\right)$

where $k_{1}$ and $k_{2}$ are constants. At any rebar strain gage level $i$, the pile axial force is expressed as:

$P_{i}=\varepsilon_{i}\left\{\left[k_{1} \exp \left(k_{2} \varepsilon\right)\right] \times A_{c i}+E_{s} \times A_{s i}\right\}$.

If the strain gage at the top-level malfunctions, the tangent modulus is used because it uses strain data that is collected at all levels.

The procedures that were proposed by Fellenius (1989 and 2001) are used to derive the tangent modulus of concrete. The tangent modulus of a composite material (concrete and steel) is a straight-line gradient from the larger tangent modulus to the smaller modulus (Fellenius 2001).

The equation for the line of the tangent modulus is expressed as (Fellenius 2001):

$M_{t}=\left(\frac{d \sigma}{d \varepsilon}\right)=A \varepsilon+B$

where $M_{t}$ is the tangent modulus, $A$ is the gradient of the tangent modulus, $B$ is the yintercept of the tangent modulus line, $\mathrm{d} \sigma$ is the difference in the stress from one load increment to the next, $d \varepsilon$ is the difference in the strain from one load increment to the next. The strain data that is measured at each level at which a strain gage is installed is used to calculate the tangent modulus. The secant modulus is calculated using Equation (5), and can be replaced by the tangent modulus using Equation (7) and then substituted into Equation (6) to calculate the pile axial load.

In the following, the tangent modulus is used for all back analysis. The secant modulus is used only in Section 4.3.4 for direct conversion of the t-z curves using strain gage data.

\section{Review of back analysis}


The displacement around the pile/soil interface can be divided into a combination of linear and nonlinear parts (Xiao, Du, and Zhang 2003). The nonlinear part is the disturbed zone, immediately adjacent to the pile/soil interface, which can be modeled as a hyperbolic function (Lin 1997; Lin et al. 2014). The method that was proposed by Randolph and Wroth (1978) is used to simulate the linear elastic soil beyond the disturbed zone. The total displacement, $S_{z}$, is expressed as a combination of the linear elastic soil displacement, $W_{s z}$, and the displacement at the disturbed zone, $\Delta S_{z}$, as:

$S_{Z}=\Delta S_{Z}+W_{S Z}$

The nonlinear displacement at the disturbed zone is modeled as a simple hyperbolic function:

$\tau_{z}=\frac{\Delta S_{z}}{a(z)+b(z) \Delta S_{z}}$

where $\tau_{z}$ is the shaft shear stress that is developed at the pile/soil interface, $\Delta S_{z}$ is the localized shear displacement that is developed at the disturbed zone, and $a(z)$ and $b(z)$ are empirical coefficients that are determined by back analysis of the pile loading test results.

The elastic soil displacement $W_{s z}$ is expressed by Randolph and Wroth (1978) as:

$W_{s z}=\frac{r_{0}}{G} \ln \left(\frac{r_{m}}{r_{0}}\right) \tau_{z}=c \tau_{z}$

where $\mathrm{c}$ is a parameter that is expressed as (Randolph and Wroth 1978):

$c=\frac{r_{0}}{G} \ln \left(\frac{r_{m}}{r_{0}}\right)$,

where $r_{0}$ is the radius of the pile, and $r_{m}$ is the radial distance from the pile center to a point at which the shear stress that is induced by the pile can be considered negligible. Randolph and Wroth (1978) define this as $r_{m}=2.51\left(1-0.5 v_{s}\right), \mathrm{G}$ is the shear modulus of the elastic soil beyond the disturbed zone and $v_{\mathrm{s}}$ is Poisson's ratio. Therefore, the total displacement at depth $z$ is:

$S_{z}=\frac{a(z) \tau_{z}}{1-b(z) \tau_{z}}+c \tau_{z}$ 
where $\mathrm{c}$ is a constant that is calculated using Equation (11) and, the other parameters $a(z)$ and $b(z)$, are back-calculated using the pile axial load along the depth, which is measured by the rebar gages.

The plot of measured pile load versus displacement test data, is used to determine the load for each loading step and the corresponding displacement at the pile head. An interpolation Spline function is used to fit the measured load distribution along the depth, to give a function $P_{i}(z)$.

Using the spline fitting function $P_{i}(z)$ the distribution of the shaft shear stresses at each loading stage $i$ along the depth is calculated as:

$\tau_{z i}(z)=-\frac{1}{2 \pi r_{0}} \frac{d \mathrm{P}_{i}(z)}{d z}$.

Equation (13) is used to determine a series of shaft shear stress data for each loading step at any selected depth $z$. The relationship between $b(z)$ and $\tau_{f(z)}$ is expressed as:

$b(z)=R_{f} / \tau_{f(z)}$,

where $R_{f}$ has a value of $0.85 \sim 0.95$, and $\tau_{f(z)}$ is the shear strength of the interface at depth $z$.

At any depth z, the displacement $S_{z i}$ under each loading step is calculated as:

$s_{z i}=s_{t i}-\frac{1}{E_{p} A_{p}} \int_{0}^{z} \mathrm{P}_{i}(z) d z$,

where $E_{p}$ and $A_{p}$ are the elastic modulus and cross-sectional area of the pile, respectively. The parameter $a(z)$ at depth $z$ is written as:

$a_{i}(z)=\frac{\left(s_{z i}-c \tau_{z i}\right)\left(1-b(z) \tau_{z i}\right)}{\tau_{z i}}$.

The initial shear stiffness $K_{s i}(z)$ for the pile/soil interaction is the reciprocal of a(z)

$K_{s i}=1 / a_{i}(z)$

The calculation steps for back analysis are:

(1) Using the pile load-settlement test data, the applied loading is divided into several loading steps. 
(2) The test results for load distribution along the depth at each corresponding loading step i are obtained using strain gage data.

(3) Calculated values that are greater than the load that is applied at the pile head are ignored and, interpolation Spline function is used to fit the measured data to obtain a load distribution with depth function $P_{i}(z)$, which is given in Equation (6), and which uses the tangent modulus.

(4) Using the Spline fitted function $P_{i}(z)$, the distribution of the shear stresses for each loading step along the depth are obtained using Equation (13).

(5) The value of $b(z)$ at depths $z$ are obtained using Equation (14).

(6) The displacement at any depth for each loading step is calculated using Equation (15).

(7) The value of $a(z)$ is calculated using Equation (16).

(8) Using Equation (13) and the corresponding displacement that is calculated using Equation (12), the t-z curves along the depth are generated.

(9) Steps (2) to (8) are repeated until the maximum applied load is reached.

\section{Case study}

\subsection{Testing site and ground conditions}

The testing site is located in the Beitou area of Taipei city (Lin et al. 2017, Lin et al. 2010). There are different soil conditions at the north and the south side of the test site, so two groups of pile loading tests were conducted, one at the north side and the other at the south side. At the northern site, the soil properties are listed in Table 1. Underneath the soil layer, there is a layer of the Andesite cobbles and boulders that are mixed with weathering gravel and soil. Beneath the Andesite rock, there is sandstone/shale bedrock. 
Table 1. Subsurface conditions at the northern site (Lin et al. 2010).

\begin{tabular}{llcccccc}
\hline Depth $(\mathrm{m})$ & \multicolumn{1}{c}{ Description } & $\begin{array}{c}\text { Classifi } \\
\text {-cation }\end{array}$ & $\begin{array}{c}\mathrm{SPT} \\
\mathrm{N}\end{array}$ & $\begin{array}{c}\text { Water } \\
\text { content } \\
(\%)\end{array}$ & $\begin{array}{c}\text { Void } \\
\text { ratio }\end{array}$ & $\begin{array}{c}\text { Unit } \\
\text { weight } \\
\left(\mathrm{kN} / \mathrm{m}^{3}\right)\end{array}$ & $\begin{array}{c}\mathrm{C}^{*} \\
\left(\mathrm{kN} / \mathrm{m}^{2}\right)\end{array}$ \\
\hline $0.0 \sim 2.8$ & Backfill & $\mathrm{SF}$ & $1.5 \sim 2$ & - & - & - & - \\
$2.8 \sim 22.0$ & Soft silty clay & $\mathrm{CL}$ & $1 \sim 4.5$ & $36.23 \sim$ & $1.04 \sim$ & $17.37 \sim$ & $2.06 \sim$ \\
$22.0 \sim 23.85$ & Silty sand & $\mathrm{SM}$ & 9 & - & - & - & - \\
$23.85 \sim 38.6$ & $\begin{array}{l}\text { Andesite rock and gravel } \\
\text { and silty sand mixture }\end{array}$ & - & $20 \sim 50 / 8 \mathrm{~cm}$ & - & - & - & - \\
$38.6 \sim 44.0$ & Sandstone & - & $50 / 4 \mathrm{~cm}$ & - & - & - & - \\
\hline$* \mathrm{C}=$ Cohesion & & & & & & &
\end{tabular}

The soil properties for the southern site are listed in Table 2. Less weathered Andesite rock cobbles and boulders (compared to the northern side), mixed with gravel and soil, underlie the silty sand layer as shown in the table.

Table 2. Subsurface conditions at the southern site (Lin et al. 2010)

\begin{tabular}{|c|c|c|c|c|c|c|c|}
\hline $\begin{array}{l}\text { Depth } \\
\text { (m) }\end{array}$ & Description & $\begin{array}{l}\text { Classifi- } \\
\text { cation }\end{array}$ & SPT-N & $\begin{array}{l}\text { Water } \\
\text { content } \\
(\%)\end{array}$ & $\begin{array}{l}\text { Void } \\
\text { ratio }\end{array}$ & $\begin{array}{c}\text { Unit } \\
\text { weight } \\
\left(\mathrm{kN} / \mathrm{m}^{3}\right)\end{array}$ & $\begin{array}{c}\mathrm{C}^{*} \\
\left(\mathrm{kN} / \mathrm{m}^{2}\right)\end{array}$ \\
\hline $0.0 \sim 2.5$ & Backfill & $\mathrm{SF}$ & 11 & - & - & - & - \\
\hline $2.5 \sim 4.5$ & Firm silty clay & $\mathrm{CL}$ & $4 \sim 5$ & - & - & - & - \\
\hline $4.5 \sim 25.5$ & Soft silty clay & $\mathrm{CL}$ & $1 \sim 4$ & $\begin{array}{l}40.71 \sim \\
39.94\end{array}$ & $\begin{array}{l}1.15 \sim \\
1.16\end{array}$ & $\begin{array}{c}17.63 \sim \\
17.38\end{array}$ & $\begin{array}{l}4.51 \sim \\
3.34\end{array}$ \\
\hline $25.5 \sim 37.5$ & Firm silty clay & CL & $5 \sim 8$ & 37.36 & 1.10 & 17.53 & 4.32 \\
\hline $37.5 \sim 41.7$ & Stiff silty clay & ML & $10 \sim 14$ & 26.89 & 0.77 & 19.04 & 7.65 \\
\hline $41.7 \sim 43.0$ & Silty sand & - & 14 & - & - & - & - \\
\hline $43.0 \sim 70.5$ & $\begin{array}{l}\text { Andesite rock and some } \\
\text { silty sand }\end{array}$ & - & $50 / 13 \mathrm{~cm} \sim 50 / 6 \mathrm{~cm}$ & - & - & - & - \\
\hline
\end{tabular}

\section{$* \mathrm{C}=$ Cohesion}

The set-up for testing piles and the contour lines of the bedrock elevation below the ground surface is shown in Figure 1. 


\subsection{Test piles}

The pile loading tests include two tensile tests using drilled shafts and two other tensile tests using a barrette. Table 3 lists the information for the four tensile test drilled shafts and barrettes.

Table 3. Basic information about the test piles.

\begin{tabular}{ccclc}
\hline Pile Code & $\begin{array}{c}\text { Test } \\
\text { Location }\end{array}$ & $\begin{array}{c}\text { Pile } \\
\text { Dimension } \\
(\mathrm{m})\end{array}$ & Pile Type & $\begin{array}{c}\text { Pile } \\
\text { Length } \\
(\mathrm{m})\end{array}$ \\
\hline B1T & North & $1.2 \times 2.7$ & Barrette Pile & 34.5 \\
D1T & & 1.5 & Drilled Shaft & 45.7 \\
B2T & South & $1.2 \times 2.7$ & Barrette Pile & 50.3 \\
D2T & & 1.5 & Drilled Shaft & 49.7 \\
\hline
\end{tabular}

The D1T shaft was installed using a reverse circulation method. The tremie method was used for shaft concreting, using a slump between 18 and $22 \mathrm{~cm}$. The designed 28-day unconfined compressive strength of the concrete is $27,468 \mathrm{kN} / \mathrm{m}^{2}$. The barrette B1T was installed using a Masago hydraulic long bucket. The requirements for the concrete slump and the design strength of concrete are similar to those for the drilled shafts.

At the southern side, the D2T shaft was installed using the casing method and the barrette B2T was also installed using a Masago hydraulic long bucket.

To determine the total load that is carried at different depths along the shafts, both rebar gages and telltales were installed at specific depths in each shaft and barrette. These rebar gages were attached to the rebar cage in sets of four at each depth and were protected. The specific levels for the B1T pile were 1.5, 2.5, 28.5, 30.5, and $32.5 \mathrm{~m}$ below ground level. The telltale levels were at four locations: $0 \mathrm{~m}-12 \mathrm{~m}, 12 \mathrm{~m}-24.2 \mathrm{~m}, 24.2 \mathrm{~m}-28.5 \mathrm{~m}$, and $28.5 \mathrm{~m}-33 \mathrm{~m}$. For the B2T pile, the gage levels were 1.5, 23.5, 29, 34, 40, 44.4, 46.4 and $48.4 \mathrm{~m}$ below the ground surface. The gage levels and telltales for D1T and D2T were respectively similar to those for B1T and B2T. 


\subsection{Interpretation of test results}

\subsubsection{Pile concrete behavior}

The relationship between the applied load and the displacement for all four tested piles is shown in Figure 2. At both sites, the barrette has a higher capacity than the drilled shaft. Although B1T is $11.2 \mathrm{~m}$ shorter than D1T, the capacity of the former is greater than that of the latter. Figures 3 and 4 respectively show the relationship between the concrete stress and strain and between the concrete modulus and the strain for the tested piles. Figure 3(a) shows that except for the lowest gage level, where the stress-strain relationship remains almost linear, the other gage locations exhibit either strain hardening or strain softening. The maximum stresses at gage levels between $1.5 \mathrm{~m}$ and $28.0 \mathrm{~m}$ are between only 2 and $4 \mathrm{MPa}$. Since the stress-strain relationship for the concrete is different for each strain gage level, a comparison of the secant and the tangent modulus for the D1T pile is shown in Figure 4(a). The uppermost gage of the D1T pile was damaged at a micro-strain value of around 500. For B1T, the stress-strain relationships at all strain gage levels are similar with a micro-strain level of less than 100, except for the gage level near the pile head, which yields when the stress reaches $2.5 \mathrm{MPa}$. The concrete stress-strain relationships for the D2T and B2T are respectively shown in Figure 3(c) and 3(d). With reference to Figures 3(a) to 3(d), only B1T exhibits more consistent concrete strength at all depths, except for the gage at $1.5 \mathrm{~m}$ below the pile head.

As shown in Figures 4(a) to 4(d), in general, the fitted secant modulus is greater than the tangent modulus for a small strain. At higher strain values, both methods yield a similar modulus value. Figures 4(a) and 4(c) respectively show the data for a micro-strain of more than 500 and 350. Data is extrapolated to fit the secant modulus because the gages were damaged.

\subsubsection{Conversion of measured strain data into pile loads}

Using the rebar gage data and the derived tangent modulus, the pile axial force along the depth of the test piles is derived as shown by the dashed lines in Figure 5. When the applied load reaches a specific magnitude, there is a separation between the rebar and the concrete 
and/or concrete cracking, so all of the measured strain is carried by the steel rebar. In this case, the assumption for Equation 2 is not valid because the strain is taken by the steel rebar only. Subsequently, there are unreasonably high pile loads (see the dashed curves derived from original read-out of Figure 5), because the cross-sectional area of the steel reinforcement is locally decreased after elongation. In Figure 5, at the frictional resistance between the soil and the pile from the ground surface to the uppermost gage level is ignored for the given applied load at the head. Figure 3(a) shows that reasonable pile load is derived in Figure 5(a) when the applied load is less than $10 \mathrm{MN}$. However, the concrete stress-strain relationship reflects the derived high pile load value for D1T at a level of $28 \mathrm{~m}$ in Figure 5(a), where the applied load is more than $10 \mathrm{MN}$. Similar results are seen for the B1T pile in Figure 3(b) and Figure 5(b). The interpreted pile load result at a level of $34 \mathrm{~m}$ for D2T in Figure 5(c) shows an applied load of more than $10 \mathrm{MN}$, possibly because there is sudden cracking of the concrete at that level, as shown in Figure 3(c). For B2T, the concrete strain softening between $29 \mathrm{~m}$ and $44.6 \mathrm{~m}$, as shown in Figure 3(d), yields the results in Figure 5(d).

\subsubsection{Ultimate pile/soil frictional resistance via back analysis}

As described in section 4, the displacement around the pile/soil interface can be divided into linear and nonlinear parts. The nonlinear displacement in the disturbed zone is modeled as a simple hyperbolic function, which is used to determine the ultimate frictional resistance and the initial shear stiffness that is developed at the pile/soil interface. The results for the northern and the southern sites for the respective maximum applied loads are respectively, shown in Figures 6 and 7, assuming $R_{f}=0.95$ for Equation (14). The results are also compared to those for the commercial design software SHAFT (Reese et al. 2018), which is used to evaluate the axial capacity and the short-term, load-settlement curves for drilled shafts in various types of soils. SHAFT determines the axial capacity and settlement behavior for drilled shafts in eight types of soil and rock models, as suggested in the latest FHWA manual (Brown, Turner, and Castelli 2010), except for the gravelly sand that was used for the study by Rollins et al. (2005). 
As shown in the figures, the initial shear stiffness for the pile/soil interaction and the ultimate frictional resistance increase with depth at both testing sites because the unconfined compressive strength increases with depth. At the northern site, the estimated ultimate strength at the pile face is less than $100 \mathrm{kPa}$ in the soil layer. In general, the back-calculated strength of the barrette is slightly greater than that of the drilled shaft. Using the material data in Tables 1 and 2 for SHAFT, the results show that the capacity of the analyzed pile is entirely carried by the bedrock layer only, with no contribution from the frictional resistance of the soil layers, because of the high bedrock strength. The bedrock is treated as sandy soil with a high internal frictional angle, so the strength that is predicted by SHAFT is twice or three times greater than the back-calculated results. In addition to the constant concrete elastic modulus that is used for SHAFT, the difference between the numerical analysis and the back-analysis results may also be due to the soil model that is used by the software. In the numerical analysis, the barrette is assumed to be a circular shaft with an equal cross-sectional area.

At the southern site, B2T and D2T have an almost identical initial shear stiffness and ultimate strength at the pile/soil interface in the soil layer. However, D2T is stronger in the part that is socketed into rock. Again, the ultimate strength that is predicted by SHAFT is much higher than that for the back- calculation.

\subsection{4. $t$ (unit load transfer) $-z$ (pile movement) curves}

The t-z curves, that are derived using the fitted spline function $P_{i}(z)$, at different elevations are shown in Figure 8. At the northern site, B1T performs better than D1T. However, the shaft unit frictional resistance for B1T decreases when the displacement approaches 1.75 mm below $26.6 \mathrm{~m}$. D2T and B2T show similar results for smaller displacements, but B2T has a higher strength than D2T when the displacement is larger. Softening behavior is observed for the piles in the bedrock at the southern site. In general, the stiffness of the pile frictional resistance vs displacement relationship for the barrette is greater than that for the drilled shaft.

The derived t-z curves for the northern site test piles and the SHAFT results are shown in Figures 9(a) and 9(b). The notations, D1T, D1T-Data and D1T-SHAFT in Figure 9, 
respectively indicate the results for back analysis, for direct derivation, and the results for the SHAFT program. Similar notations are also used for the other piles. As shown in Figures 9(a) and 9(b), the t-z curves for the bedrock layer that are predicted by SHAFT are smaller than those for the other two methods. Although SHAFT estimates a higher frictional resistance, as shown in Figures 6 and 7, it gives a lower t-z relationship. In addition to the constant concrete elastic modulus used in the SHAFT, the difference between the numerical analysis and the gage data interpretation results may be due to the soil model that is used for the software. In general, the $t-z$ curves that are derived from the gage data directly and from the back-analysis are similar. There is a difference between the two results possibly because the direct derivation from gage data occurs only at selected points along the shaft but a continuous function is used for the back-analysis method. Each method also uses a different concrete modulus.

\section{Conclusions}

Based on the interpretation of pile loading test results in this study, the following conclusions are drawn:

1. For a tensile loading test, the rebar gage can yield an anomalous result because the strain that results from the applied load is entirely carried by the steel rebar only. The anomality may be due to separation between the steel and the concrete or concrete cracking, which ultimately results in a decrease in the cross-section of the steel reinforcement.

2. A reasonable axial force along the depth of tensile test piles can be fitted using the Spline function, when anomalous data is ignored.

3. Using the fitting pile force function and assuming that the behavior between pile and soil interface can be represented by a hyperbolic model, whose parameters are calculated using back-analysis, the t-z curves at each level can be derived.

4. The back-analysis results show that the pile/soil interaction initial shear stiffness and the ultimate frictional resistance increase with depth at both testing sites. There is a similar variation in the unconfined compressive strength with depth. 
5. The case studies using the software SHAFT are only relevant when the bedrock is assumed to be sandy soil with a high internal friction angle. SHAFT predicts higher ultimate frictional resistance along the depth.

\section{Nomenclature}

$\begin{array}{ll}A & \text { slope of the tangent modulus } \\ A_{c} & \text { area of concrete } \\ A_{s} & \text { area of steel } \\ B & \text { y-intercept of the tangent modulus } \\ C & \text { cohesion } \\ E_{c} & \text { secant modulus of concrete } \\ E_{S} & \text { elastic modulus of steel } \\ \varepsilon_{S} & \text { measured strain from the rebar strain gage } \\ f_{S} & \text { steel force } \\ M_{t} & \text { tangent modulus } \\ \tau_{z} & \text { shaft shear stress }\end{array}$

\section{References}

Brown, D.A., J.P. Turner, and R.J. Castelli. 2010. Drilled Shafts: Construction Procedures and LRFD Design Methods. Report No. FHWA-NHI-10-016. USA: Federal Highway Administration, US Department of Transportation.

Brown, M.J., A.F.L. Hyde, and W.F. Anderson. 2006. "Analysis of a Rapid Load Test on an Instrumented Bored Pile in Clay.” Geotechnique 56(9): 627-638. doi:10.1680/geot.2006.56.9.627.

Deschamps, R., and T.D. Jr. Richards. 2005. "Installation Measurement and Interpretation of Sister Bar Strain Gauges in Micro-Piles." Proceedings of the GEO Construction QA/QC Technical Conference, Dallas, Texas, ADSC, 167-178.

Fellenius, B. H. 2001. "From Strain Measurements to Load in an Instrumented Pile." Geotechnical News Magazine 19(1): 35-38. 
Fellenius, B.H. 1989. “Tangent Modulus of Piles Determined from Strain Data.” In Foundation Congress, edited by F.H. Kulhawy, Vol. 1:500-510.

Lam, C., and S.A. Jefferis. 2011. "Critical Assessment of Pile Modulus Determination Methods." Canadian Geotechnical Journal 48(10): 1433-1448. doi:10.1139/t11-050.

Lin, S.S. 1997. "Use of Filamented Beam Elements for Bored Pile Analysis." Journal of Structural Engineering ASCE 123(9): 1236-1244. doi:10.1061/(ASCE)07339445(1997)123:9(1236).

Lin, S.S., J.C. Liao, K.J. Wang, and Y.K. Lin. 2010. "Load Capacity of Drilled Shafts Socketed in Andesite Rock." Art of Foundation Engineering Practice Congress 2010, edited by Mohamad H. Hussein, J. Brian Anderson, and William M. Camp, Florida, 20-24 February 2010, 359-370. USA:ASCE.

Lin, S.S., F.C. Lu, C.J. Kuo , T.W. Su, and E. Mulowayi. 2014. “Axial Capacity of Barrette Piles Embedded in Gravel Layer." Journal of GeoEngineerig 9(3): 103-107. doi:10.6310.jog.2014.9(3).3.

Lin, S.S., J.C. Liao, A.S. Balasubramaniam, and Y.K. Lin. 2017. "Comparison Between the Tensile Behaviors of Rock-Socketed Barrette and Drilled Shaft.” Proceedings of 19th ICSMGE, Seoul, Korea, 17-22 September 2017: 2805-2808. ISSMGE.

Omer, J.R., R. Delpak, and R.B. Robinson. 2002. “Instrumented Load Tests in Mudstone: Pile Capacity and Settlement Prediction.” Canadian Geotechnical Journal 39(6): 12541272. doi:10.1139/t02-072.

Randolph, M.F., and C.P. Wroth. 1978. "Analysis of Deformation of Vertically Loaded Piles.” Journal of Geotechnical Engineering Division 104(12): 1465-1488.

Reese, L.C., S.T. Wang, L. Vasquez, and J.A. Arrellaga. 2018. A Program for the Study of Drilled Shafts under Axial Loads, Texas, USA: Ensoft Inc.

Rollins, K. M., R. T. Clayton, R. C. Mikesell, and B. C. Blaise. 2005. "Drilled Shaft Side Friction in Gravelly Soils." Journal of Geotechnical and Geoenvironmental Engineering ASCE 131(8): 987-1003. doi:10.1061/(ASCE)10900241(2005)131:8(987). 
Sellers, B. 2003. "The Measurement of Stress in Concrete." In Proceedings of the 6th International Symposium on Field Measurement in Geomechanics, Oslo, Norway, 2326 September 2003: 643-656. USA: CRC press.

Siegel, T.C. 2010. "Load Testing and Interpretation of Instrumented Augered Cast-in-Place Piles.” DFI Journal 4(2): 65-71. doi:10.1179/DFI.2010.011.

Sinnreich, J. 2012. "Strain Gage Analysis for Nonlinear Pile Stiffness." Geotechnical Testing Journal 35(2): 1-8. doi:10.1520/GTJ103412.

Xiao, Z.R., M.F. Du, and Z. Zhang. 2003. "A Back-Analysis Method to Determine the Parameters for the Pile Foundation Analysis." BGA International Conference on Foundations: Innovations, observations, design and practice, edited by T.A. Newson, Dundee, Scotland, 2-5 September 2003: 951-962. England: Thomas Telford. 
Figure 1. Pile test site and set-up of the pile tests. (Redraw from Lin et al.

Figure 2. Applied load versus displacement at the head of tested piles.

Figure 3(a). Concrete stress-strain relationship of D1T pile

Figure 3(b). Concrete stress-strain relationship of B1T pile

Figure 3(c). Concrete stress-strain relationship of D2T pile.

Figure 3(d). Concrete stress-strain relationship of B2T pile

Figure 4(a). Tangent and secant modulus of D1T pile

Figure 4(b). Tangent and secant modulus of B1T pile.

Figure 4(c). Tangent and secant modulus of D2T pile

Figure 4(d). Tangent and secant modulus of B2T pile

Figure 5(a). Axial load along depth of D1T pile under different loading levels.....

Figure 5(b). Axial load along depth of B1T pile under different loading levels......

Figure 5(c). Axial load along depth of D2T pile under different loading levels.....

Figure 5(d). Axial load along depth of B2T pile under different loading levels.....

Figure 6(a). Soil unconfined compressive strength along depth of the test piles at north site.

Figure 6(b). Initial shear stiffness at soil/pile interface of the test piles at northern site

Figure 6(c). Frictional resistance by SHAFT of the test piles at northern site

Figure 6(d). Frictional resistance by back-analysis of the test piles at northern site

Figure 7(a). Soil unconfined compressive strength along depth of the test piles at southern site.

Figure 7(b). Initial shear stiffness at soil/pile interface of the test piles at southern site

Figure 7(c). Frictional resistance by SHAFT of the test piles at southern site..... 
Figure 7(d). Frictional resistance by back-analysis of the test piles at southern site.

Figure 8(a). t-z curve of D1T at northern site.

Figure $8(\mathrm{~b}) . \mathrm{t}-\mathrm{z}$ curve of B1T at northern site.

Figure $8(\mathrm{c}) . \mathrm{t}-\mathrm{z}$ curve of D2T at southern site.

Figure 8(d). t-z curve of B2T at southern site.

Figure 9(a). Comparison of t-z curved among derived from gage data, back analysis and SHAFT of D1T

Figure 9(b). Comparison of t-z curved among derived from gage data, back analysis and SHAFT of B1T.

Figure 9(c). Comparison of t-z curved among derived from gage data, back analysis and SHAFT of D2T.

Figure 9(d). Comparison of t-z curved among derived from gage data, back analysis and SHAFT of B2T 

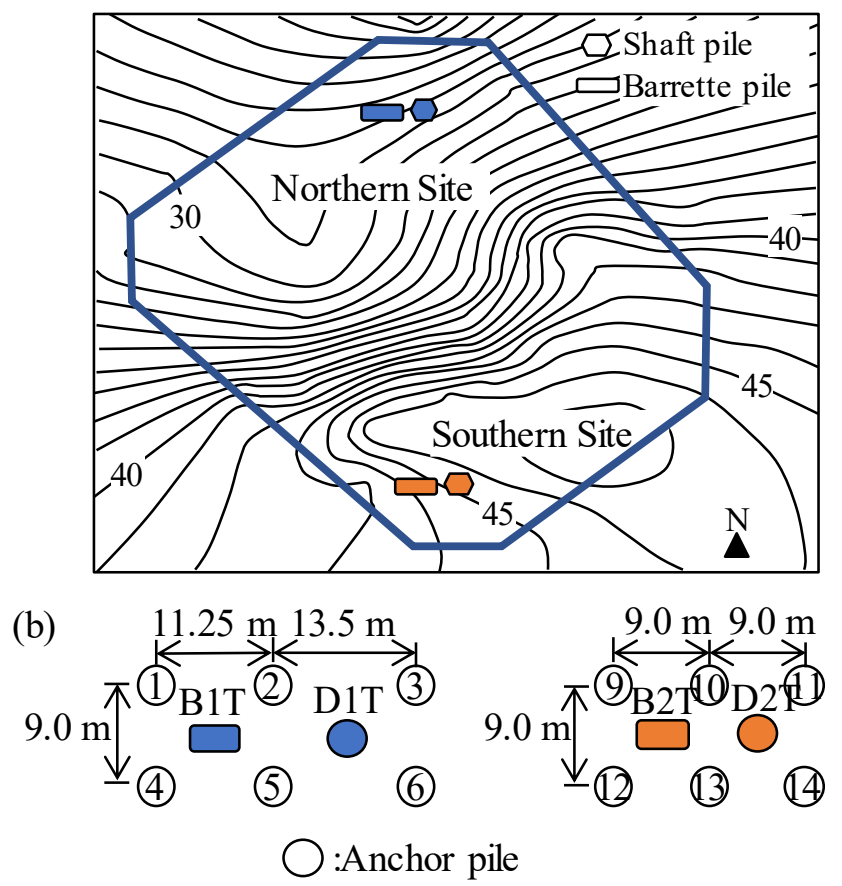

Figure 1. Pile test site and set-up of the pile tests. (Redraw from Lin et al. 2010) 


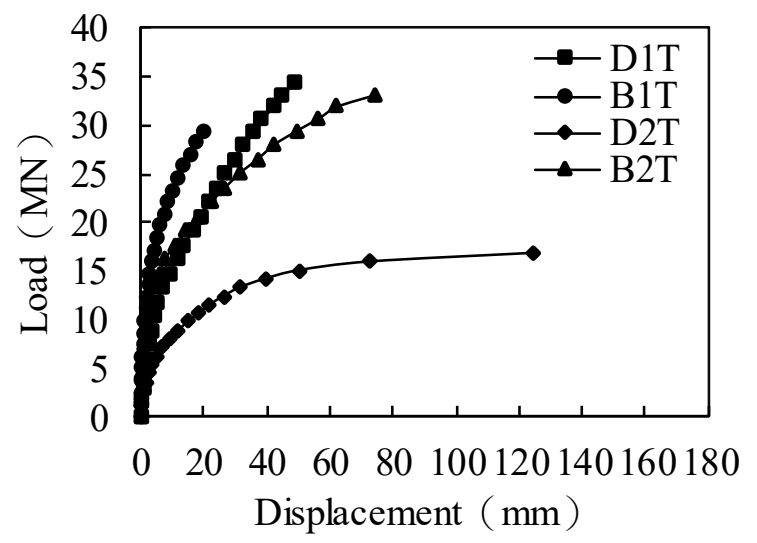

Figure 2. Applied load versus displacement at the head of tested piles. 


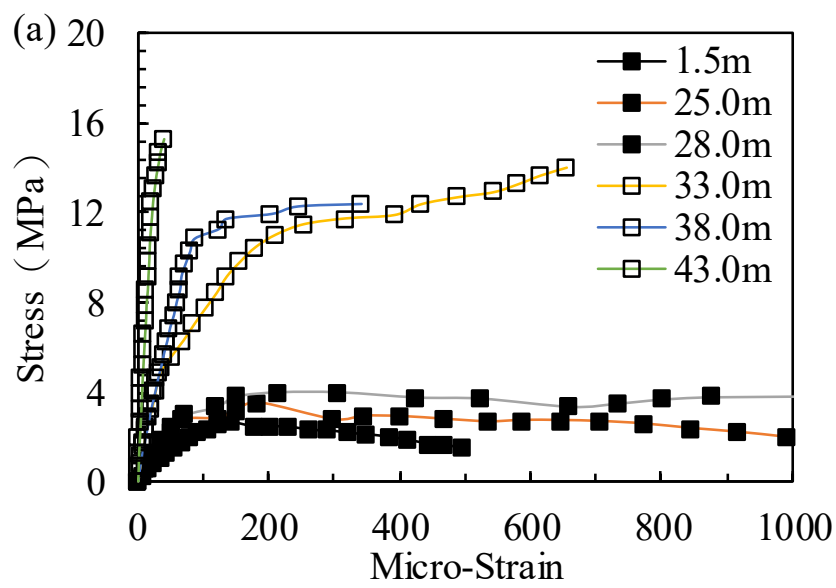

Figure 3(a). Concrete stress-strain relationship of D1T pile. 


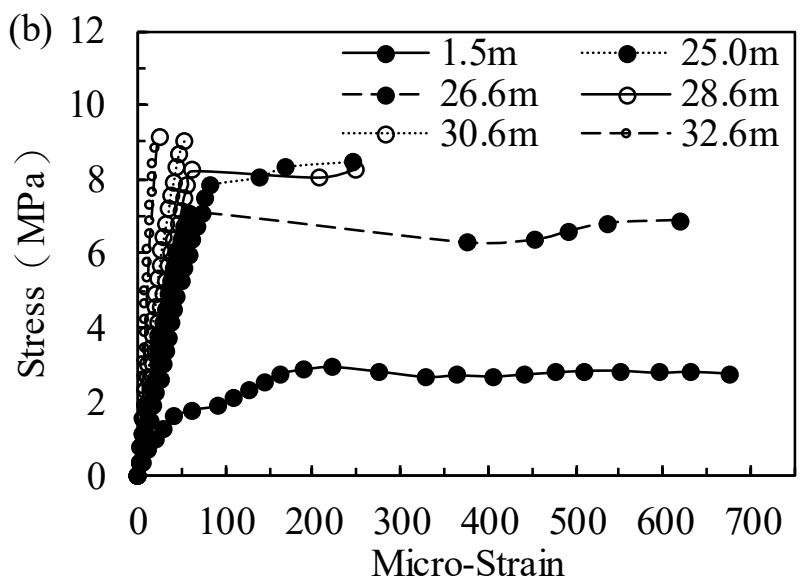

Figure 3(b). Concrete stress-strain relationship of B1T pile. 


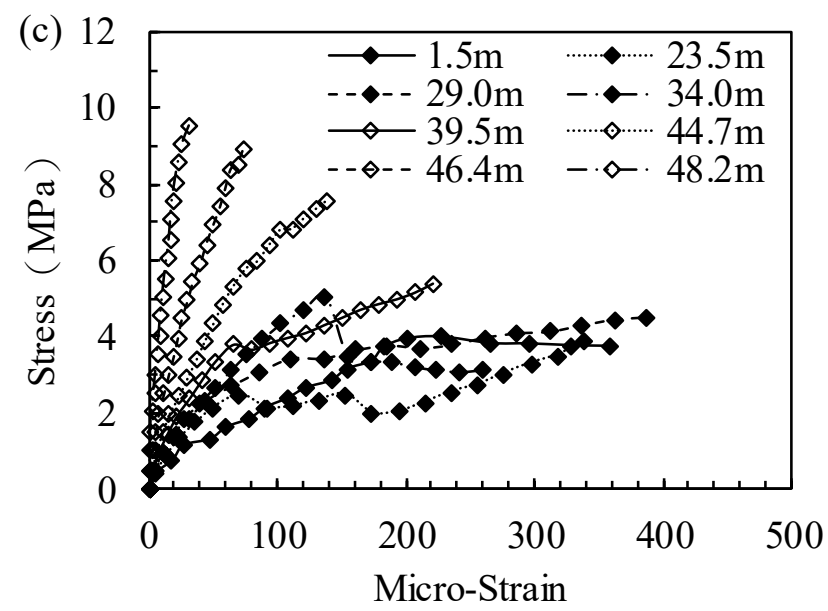

Figure 3(c). Concrete stress-strain relationship of D2T pile. 


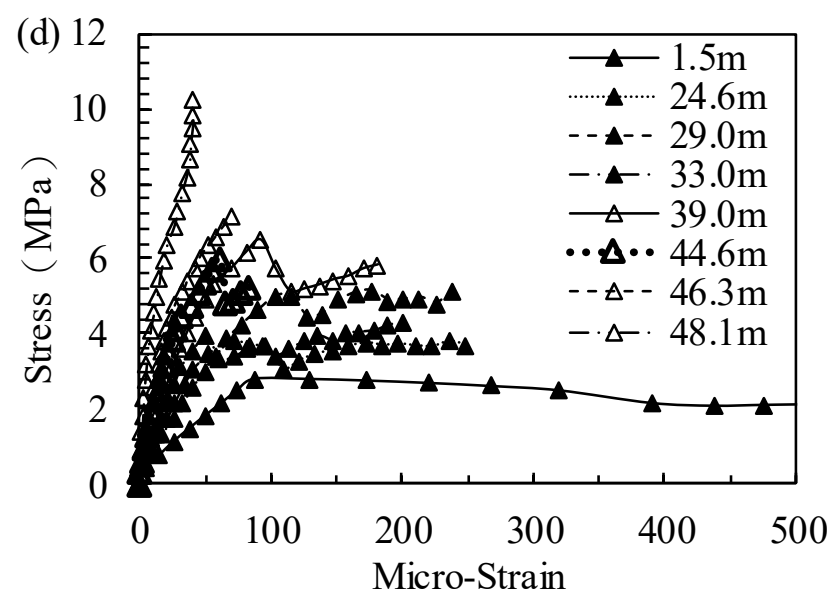

Figure 3(d). Concrete stress-strain relationship of B2T pile. 


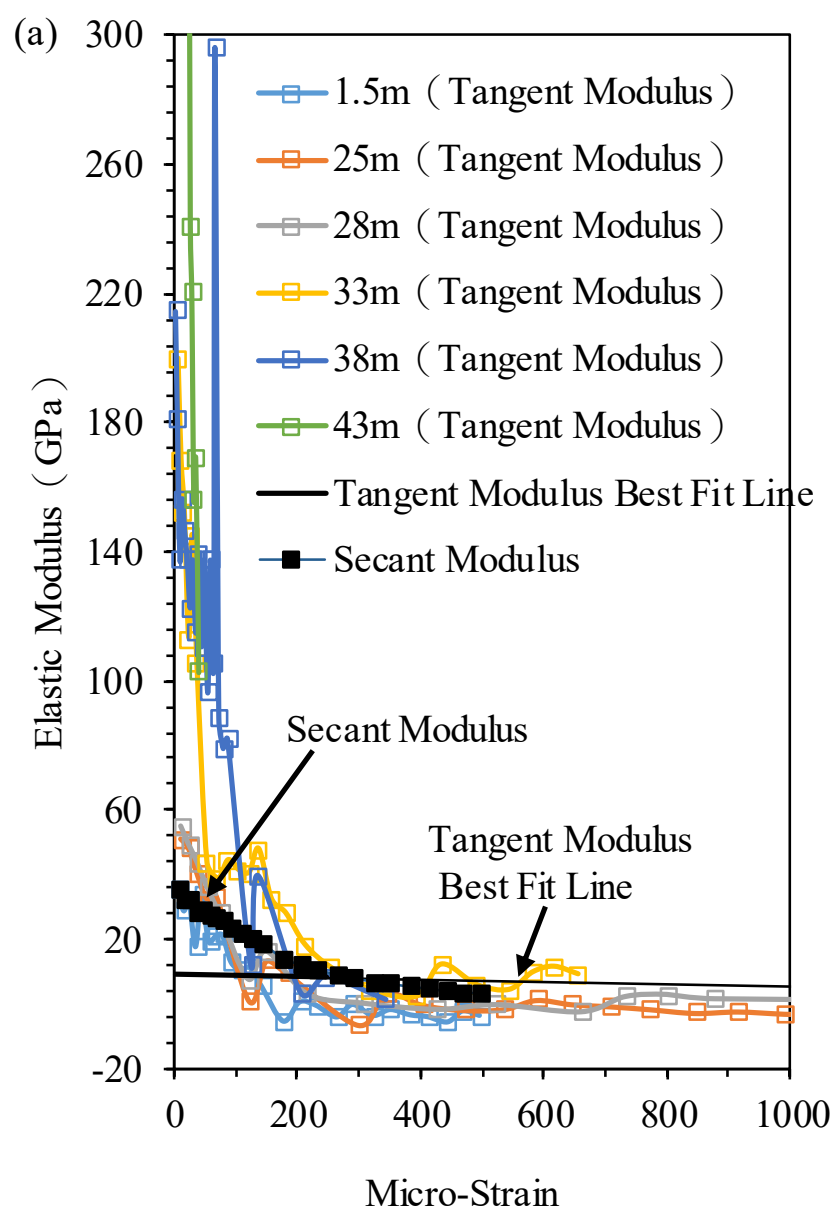

Figure 4(a). Tangent and secant modulus of D1T pile. 


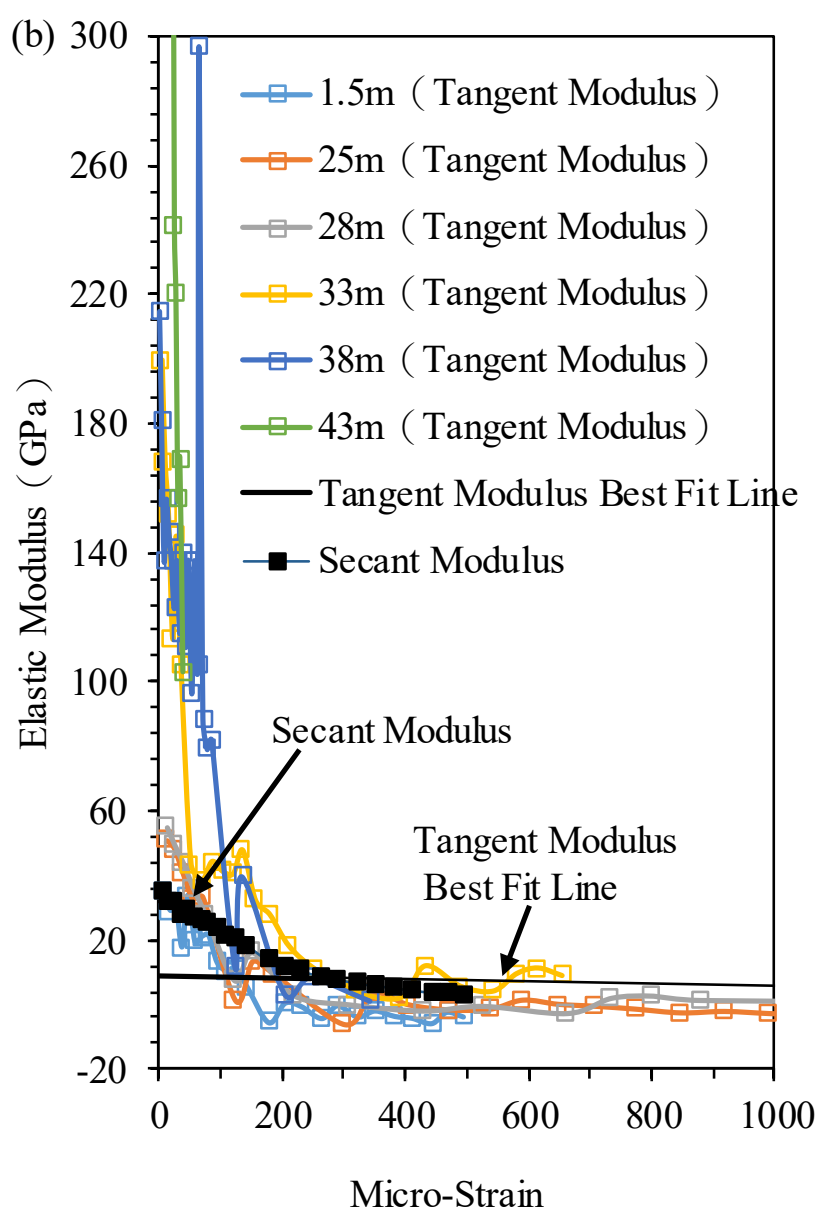

Figure 4(b). Tangent and secant modulus of B1T pile. 


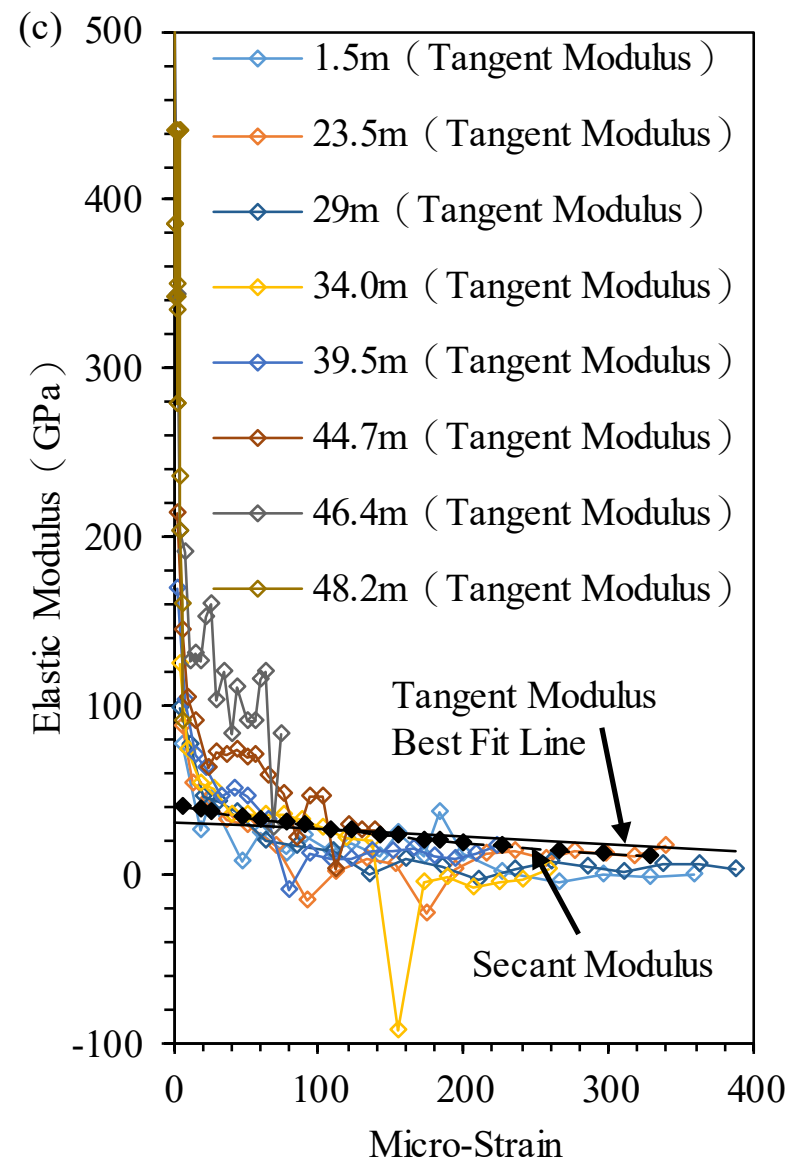

Figure 4(c). Tangent and secant modulus of D2T pile. 


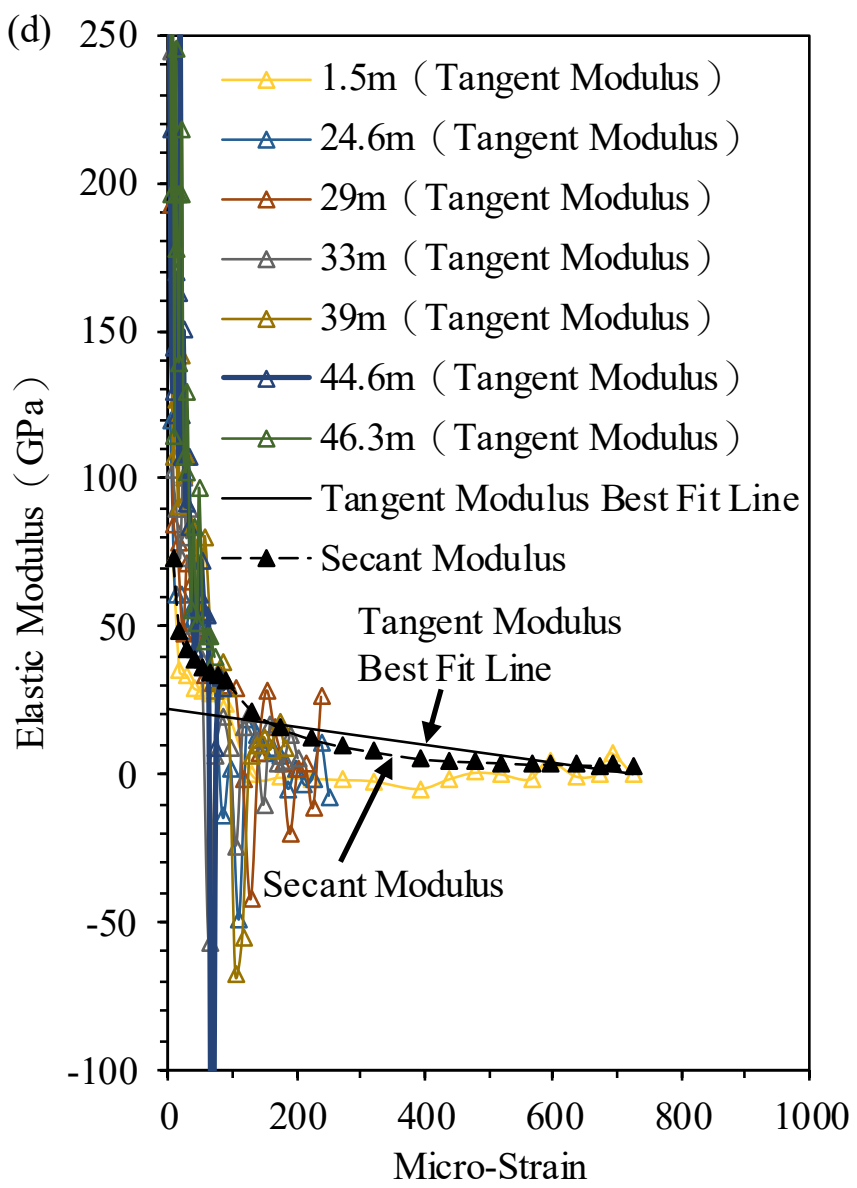

Figure 4(d). Tangent and secant modulus of B2T pile. 


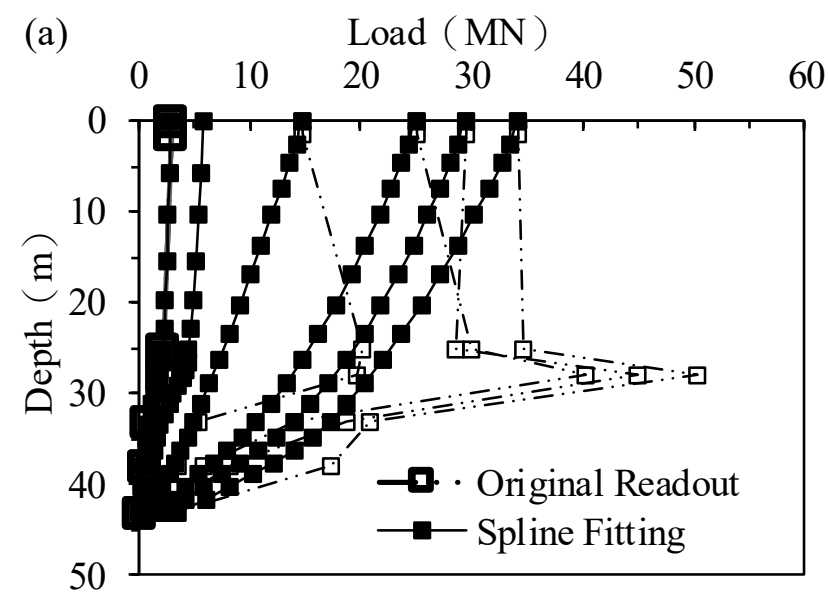

Figure 5(a). Axial load along depth of D1T pile under different loading levels. 


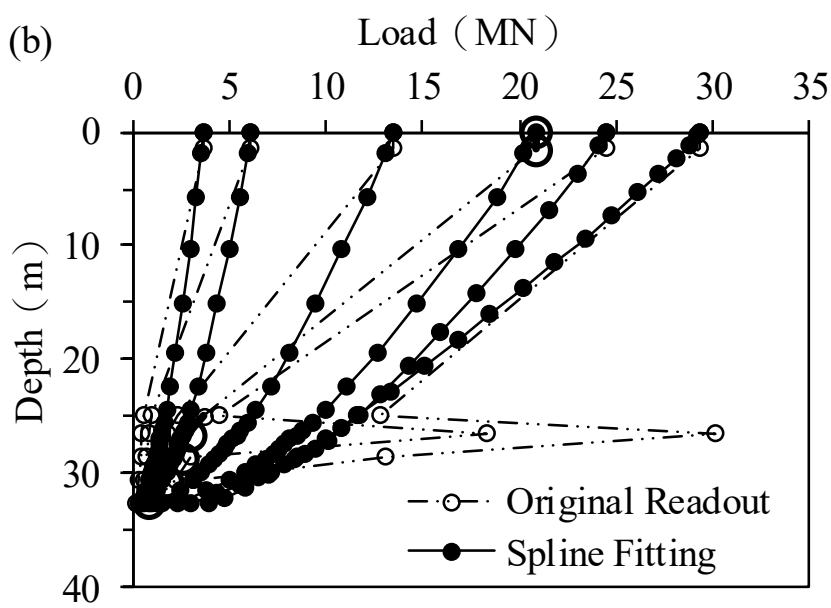

Figure 5(b). Axial load along depth of B1T pile under different loading levels. 


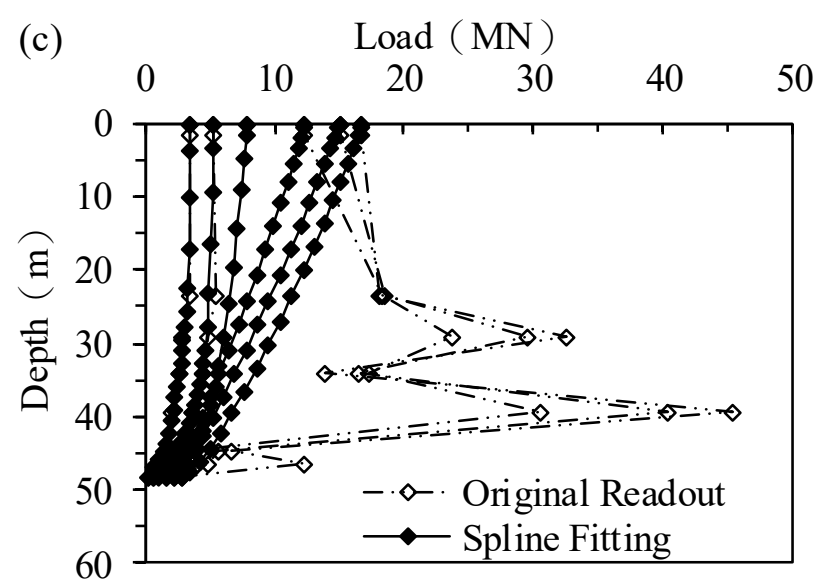

Figure 5(c). Axial load along depth of D2T pile under different loading levels. 


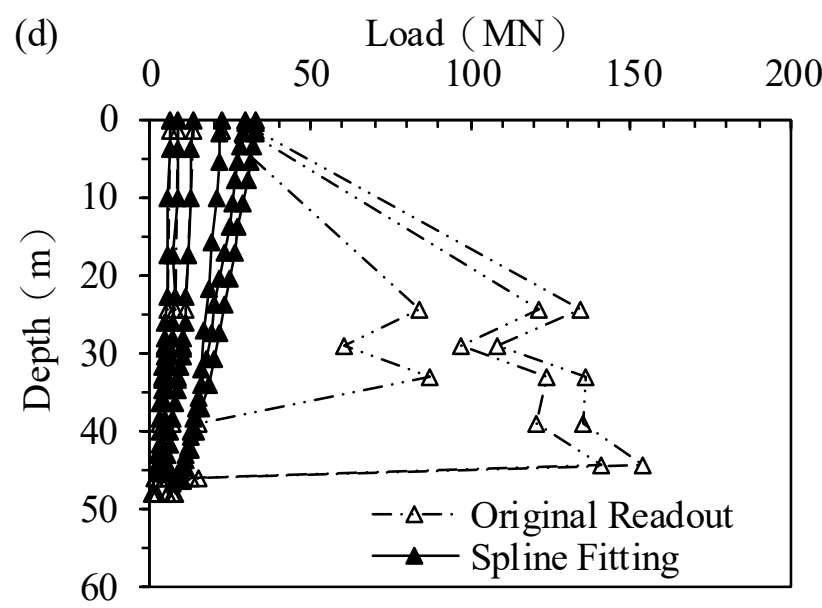

Figure 5(d). Axial load along depth of B2T pile under different loading levels. 
(a) Unconfined compressive strength $(\mathrm{kPa})$

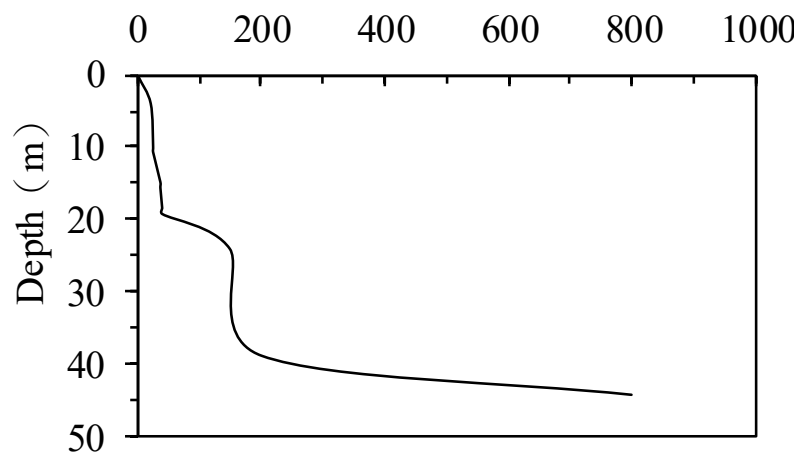

Figure 6(a). Soil unconfined compressive strength along depth of the test piles at north site. 
(b) Initial shear stiffness of the

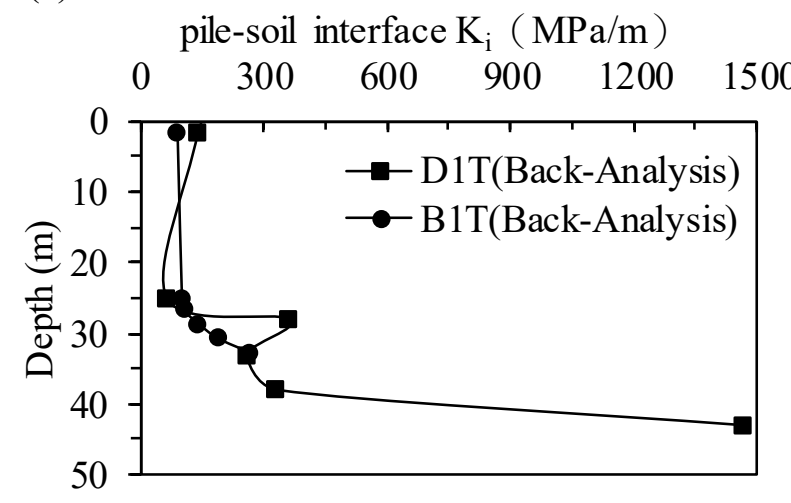

Figure 6(b). Initial shear stiffness at soil/pile interface of the test piles at north site. 


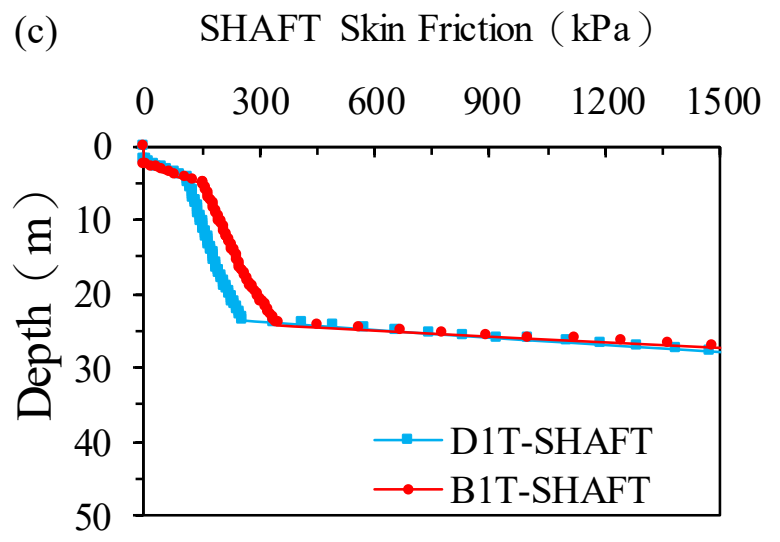

Figure 6(c). Frictional resistance by SHAFT of the test piles at north site. 


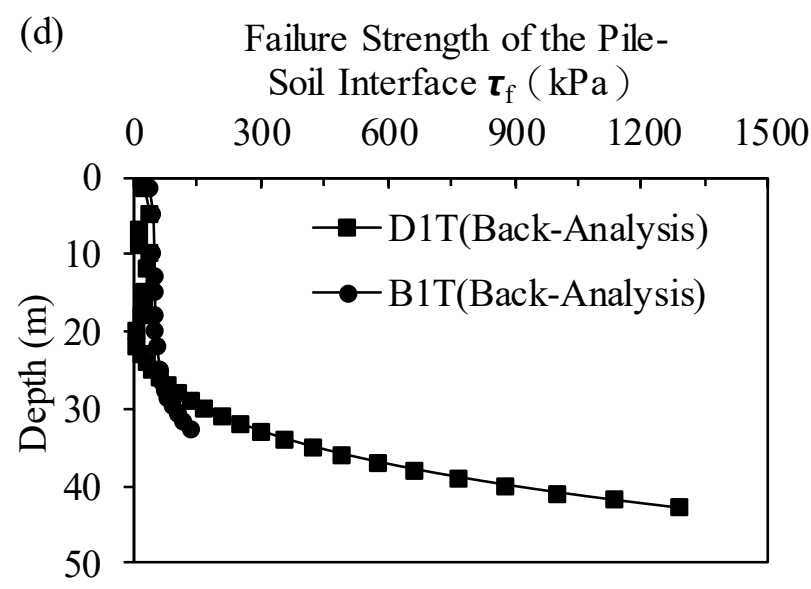

Figure 6(d). Frictional resistance by back-analysis of the test piles at north site. 
(a) Unconfined compressive strength

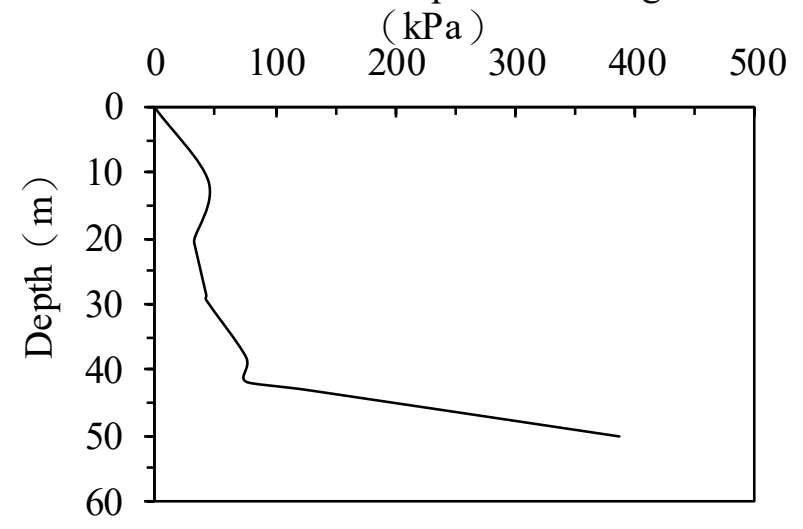

Figure 7(a). Soil unconfined compressive strength along depth of the test piles at south site. 
(b) Initial shear stiffness of the pile-soil

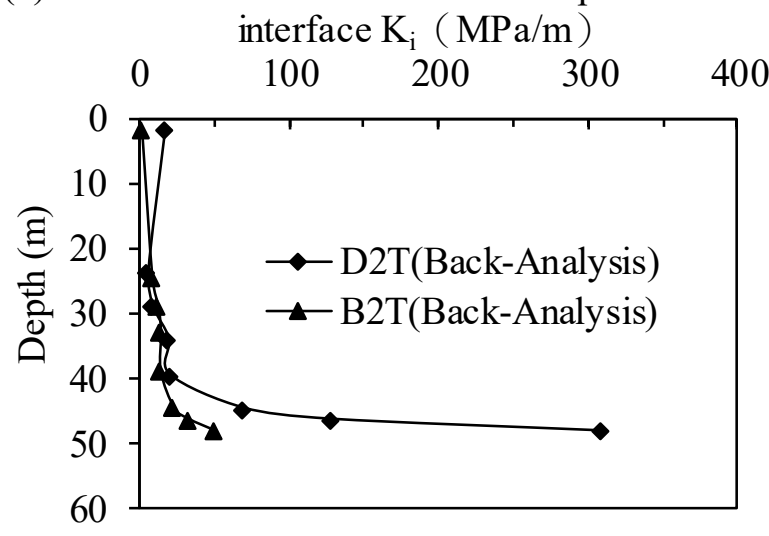

Figure 7(b). Initial shear stiffness at soil/pile interface of the test piles at south site. 


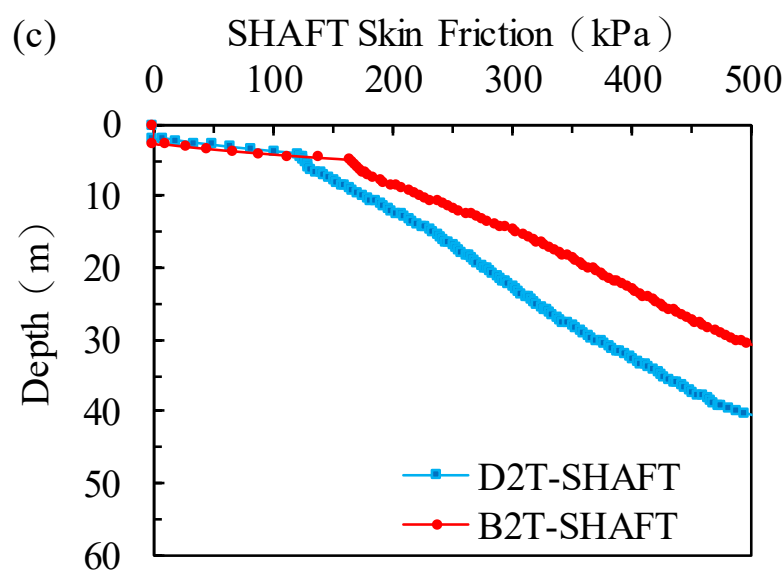

Figure 7(c). Frictional resistance by SHAFT of the test piles at south site. 
(d) Failure Strength of the Pile-Soil Interface

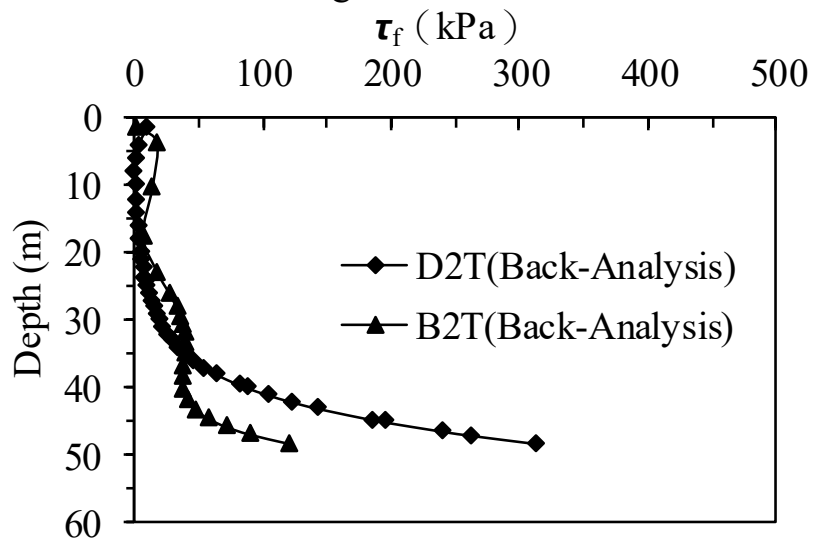

Figure 7(d). Frictional resistance by back-analysis of the test piles at south site. 


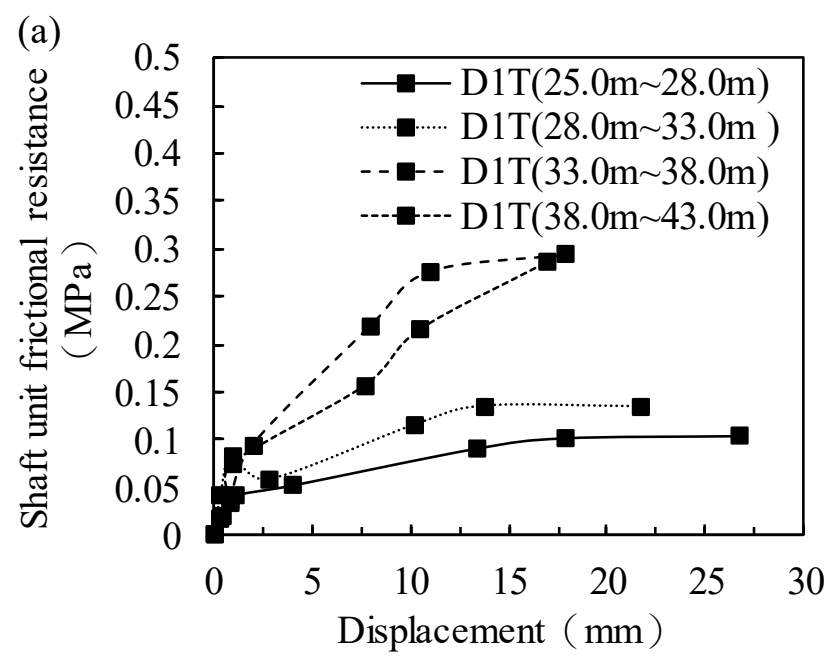

Figure 8(a). t-z curve of D1T at northern site. 


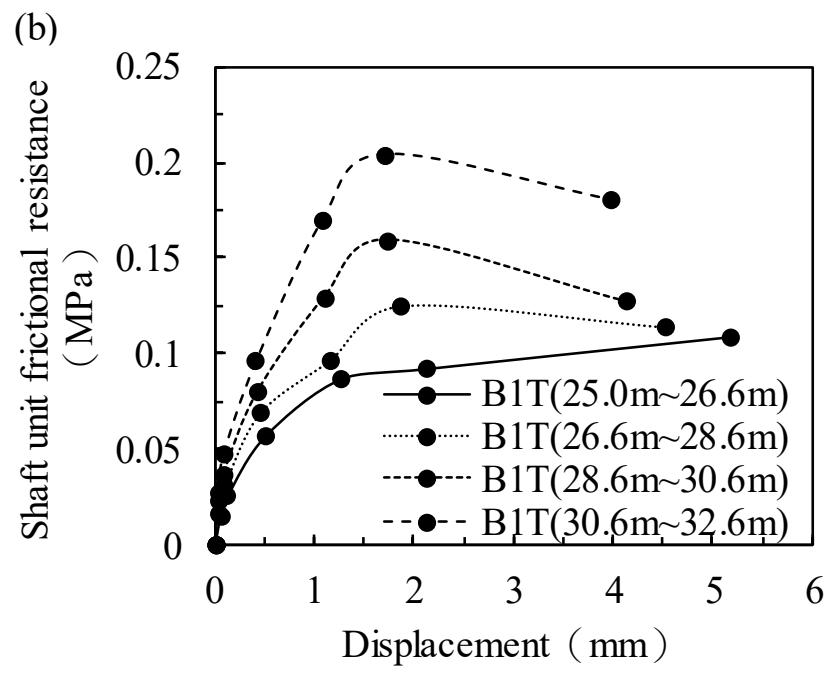

Figure 8(b). t-z curve of B1T at northern site. 


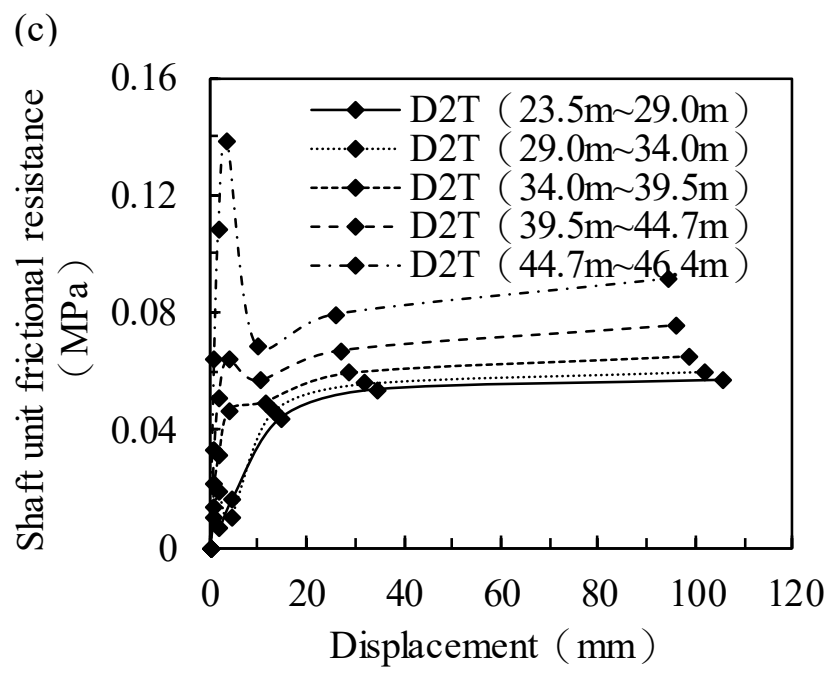

Figure 8(c). t-z curve of D2T at southern site. 
(d)

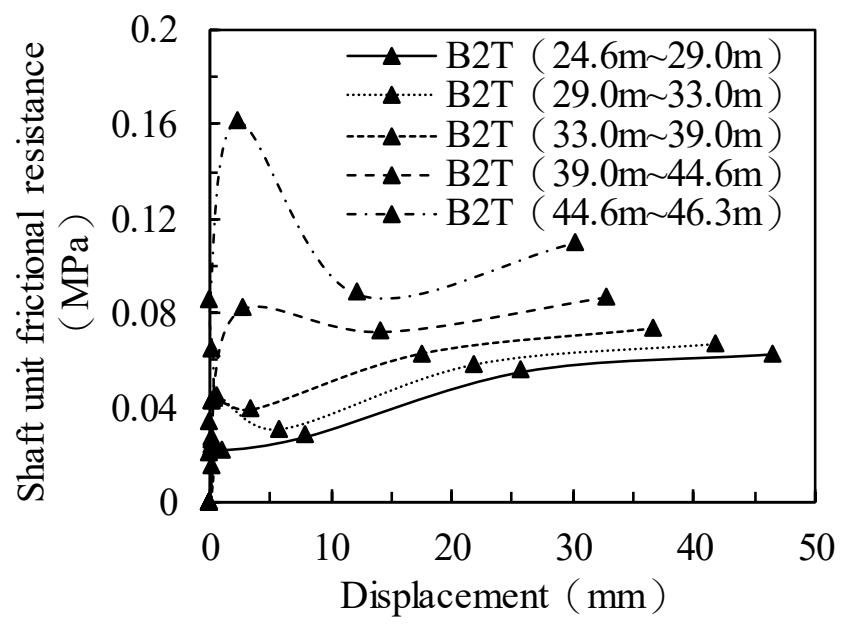

Figure 8(d). t-z curve of B2T at southern site. 


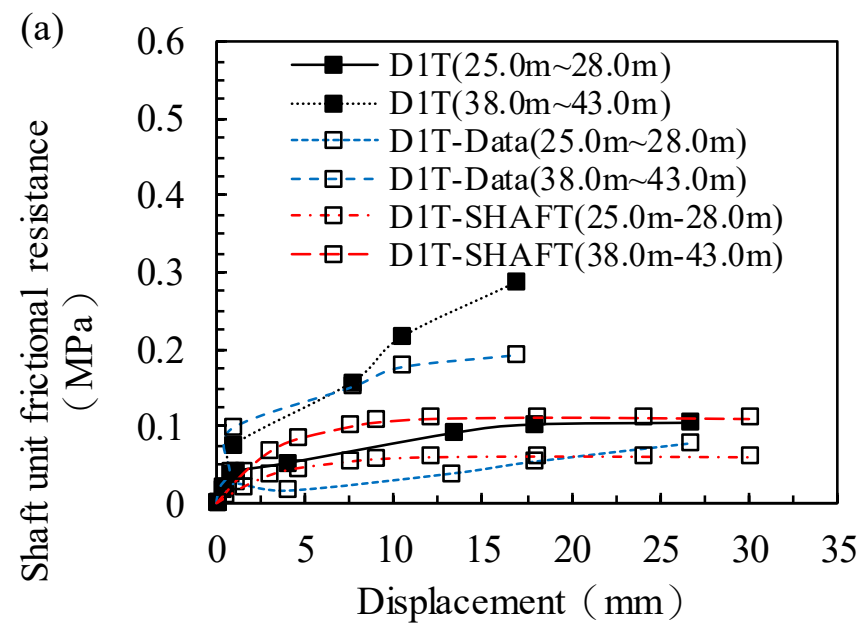

Figure 9(a). Comparison of t-z curved among derived from gage data, back analysis and SHAFT of D1T. 


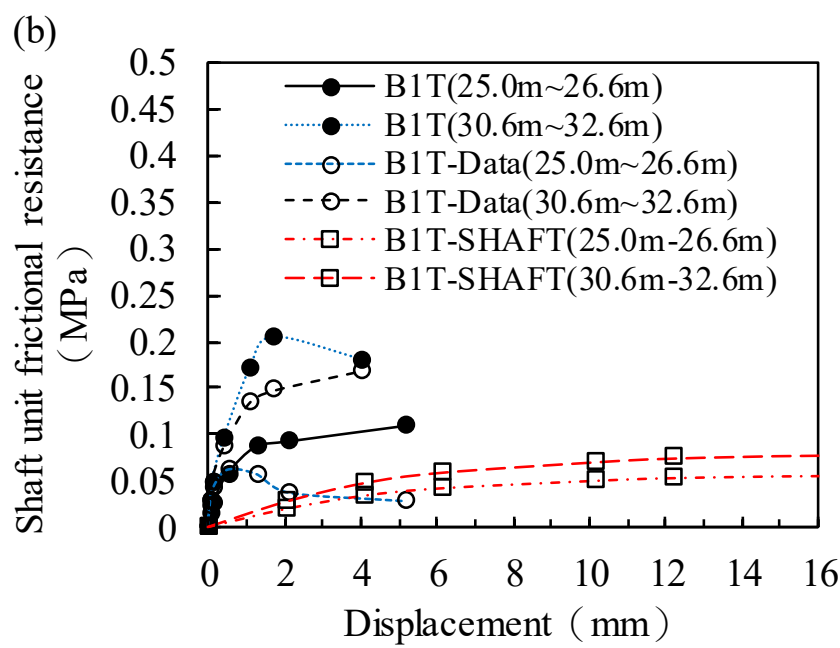

Figure 9(b). Comparison of t-z curved among derived from gage data, back analysis and SHAFT of B1T. 


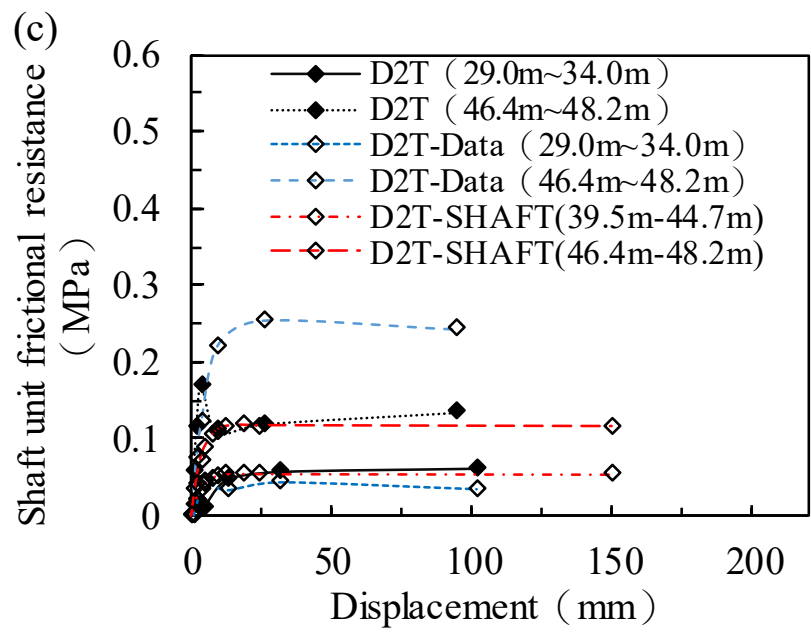

Figure 9(c). Comparison of t-z curved among derived from gage data, back analysis and SHAFT of D2T. 
(d)

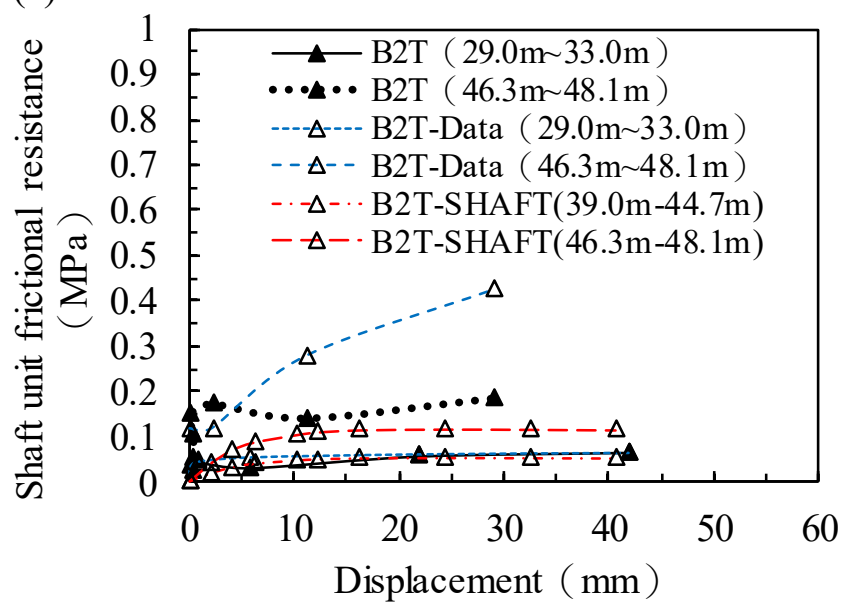

Figure 9(d). Comparison of t-z curved among derived from gage data, back analysis and SHAFT of B2T. 